\title{
COMPOSIÇÃO QUÍMICA VOLÁTIL, EM DIFERENTES ESTÁDIOS DE MATURAÇÃO, DE MANGA 'TOMMY ATKINS' PRODUZIDA NO VALE DO SÃO FRANCISCO
}

\author{
Kirley Marques Canuto* \\ Embrapa Semi-Árido, CP 23, 56302-970 Petrolina - PE, Brasil \\ Manoel Alves de Souza Neto e Deborah dos Santos Garruti \\ Embrapa Agroindústria Tropical, CP 3761, 60511-110 Fortaleza - CE, Brasil
}

Recebido em 10/1/09; aceito em 19/5/09; publicado na web em 13/10/09

\begin{abstract}
VOLATILE CHEMICAL COMPOSITION OF MANGO FRUIT 'TOMMY ATKINS', CULTIVATED IN SÃO FRANCISCO VALLEY, AT DIFFERENT STAGES OF MATURITY. The effect of the maturation stages on the volatile chemical composition of mango fruit cv. Tommy Atkins, cultivated in São Francisco Valley, was investigated using SPME. GC/MS and GC-FID analysis allowed the identification of 32 compounds, consisting mainly of monoterpenes. $\delta$-3-Carene was the major component in all the stages, while $\alpha$-terpinolene, trans- $\beta$-caryophyllene e $\alpha$-pinene succeded each other as the second most abundant constituent, during the ripening. The aroma of the ripe fruit was characterized by presence of short-chain ethyl esters $\left(\mathrm{C}_{2}-\mathrm{C}_{6}\right)$, whereas the green mango contained the highest concentration of $\delta$-3-carene. Furthermore, some terpenes were detected exclusively at one of the stages.
\end{abstract}

Keywords: mango; volatile compounds; SPME.

\section{INTRODUÇÃO}

A mangicultura representa a segunda maior cultura tropical, sendo a manga (Mangifera indica L.) um dos frutos mais consumidos no mundo, na forma in natura ou como polpa, suco, néctar, doce e geleia. ${ }^{1} \mathrm{O}$ Brasil é o sétimo maior produtor mundial de manga, produzindo mais de 1,5 milhão t/ano (2007), sendo o Vale do São Francisco a principal região produtora, respondendo por cerca de metade desta produção. ${ }^{2}$ A cultivar Tommy Atkins é a variedade mais cultivada no Brasil, em virtude de sua alta produtividade e resistência ao transporte, favorecendo sua exportação para mercados consumidores distantes, por via marítima. ${ }^{2}$

O elevado consumo mundial de manga é atribuído às suas agradáveis propriedades sensoriais como o aroma, o qual é um atributo decisivo para boa aceitação de qualquer fruta. ${ }^{3} \mathrm{O}$ aroma é a percepção sensorial de compostos voláteis, que atingem os receptores olfativos através do trato respiratório, compondo juntamente com o gosto, o sabor característico do alimento. ${ }^{3}$

Os métodos de extração de voláteis convencionalmente utilizados são a hidrodestilação e o arraste a vapor que, apesar dos elevados rendimentos e volatilização de compostos de altos pesos moleculares, produzem frequentemente artefatos. Fluido supercrítico é uma alternativa menos severa para obtenção de compostos menos voláteis ou fortemente ligados à matriz, todavia não é eficiente para substâncias polares. Análises de headspace estático e dinâmico, nas versões efetuadas por extração de fase sólida ou microextração em fase sólida (SPME), são as técnicas mais modernas e brandas para a captação de voláteis. ${ }^{3}$ Não obstante, SPME mostra-se ainda perfeitamente compatível com a aplicação direta de analito em coluna de CG, através de dessorção térmica, permitindo injeção de amostra isenta de contaminantes. Adicionalmente, SPME propicia rapidez e praticidade na análise da constituição química autêntica do aroma da fruta. ${ }^{4}$

A composição volátil de manga é muito susceptível a variações, sendo influenciada por diversos fatores como variedade estudada, procedência geográfica, estádio de maturação, condições de conservação e o método de extração. ${ }^{5}$ Além disso, já foram detectadas

*e-mail: kirley.canuto@cpatsa.embrapa.br diferenças na composição química das diferentes partes do fruto (casca e polpa: porções interna, intermediária, externa, superior, meio e inferior do mesocarpo). ${ }^{6}$

Em virtude disso, a constituição química da manga é muito complexa, tendo já sido identificados mais de 300 compostos, pertencentes às mais variadas classes, sendo encontrados tanto na forma livre ou como heterosídios: terpenoides, ésteres etílicos de ácidos graxos $\left(\mathrm{C}_{2}-\right.$ $\mathrm{C}_{16}$ ), $\gamma$ e $\delta$-lactonas, bem como aldeídos, cetonas e álcoois alifáticos de cadeia curta $\left(\mathrm{C}_{2}-\mathrm{C}_{6}\right) .{ }^{3,5,7,8}$ Mono e sesquiterpenoides representam cerca de $70-90 \%$ dos componentes voláteis de manga, os demais compostos conferem os odores peculiares ao aroma de cada cultivar. ${ }^{3,8}$

Cultivares de manga de origem asiática são caracterizadas pela presença abundante de ésteres, furanonas e lactonas, conferindo notas de aroma de abacaxi e pêssego. Compostos glicosilados, como monoterpenos oxigenados, ésteres, aldeídos e norisoprenoides são os constituintes característicos da manga africana. ${ }^{9}$ Contudo, as cultivares oriundas das Américas são compostas principalmente por terpenos, entre os quais se destaca o $\delta$-3-careno. ${ }^{8}$ Entre vinte cultivares existentes em Cuba, $\delta$-3-careno foi o componente principal em metade delas, enquanto que limoneno (6), $\alpha$-terpinoleno (4) e $\alpha$-felandreno (1) foram os compostos mais abundantes nas demais. ${ }^{7}$

Análise por CG/EM de 15 variedades, cultivadas no Brasil, revelou a existência de três grupos, segundo uma classificação por componente majoritário: $\alpha$-terpinoleno (Cheiro, Chana, Bacuri, Cametá, Gojoba, Carlota, Coquinho e Comum), $\delta$-3-careno (Haden, Tommy Atkins e Keitt) e mirceno (Cavalo, Rosa, Espada e Paulista). ${ }^{10}$ Por outro lado, em análise olfatométrica realizada com mangas comerciais brasileiras (Carlota, Haden, Tommy Atkins, Coração de boi, Rubi e Espada), o butanoato de etila foi identificado como sendo o componente de maior impacto odorífero. ${ }^{11}$

A biossíntese de compostos voláteis também é fortemente afetada pelas mudanças bioquímicas e fisiológicas que ocorrem durante o amadurecimento do fruto, tais como amaciamento da polpa, desenvolvimento de pigmentos, incremento na taxa de respiração e produção de etileno, alterações no metabolismo de carboidratos, lipídios. Neste período, o qual dura entre 9 e 12 dias (dependendo da variedade e da maturidade no momento da colheita, entre outros fatores), já foram observadas diferenças químicas significativas no aroma das cultivares 
Kensington Pride e Keitt. ${ }^{12,13}$ A caracterização da composição volátil de cada estádio de maturação, feita por nariz eletrônico e cromatografia gasosa, demonstrou ser útil na determinação do momento correto da colheita dos frutos das variedades Cogshall, Kent e Keitt. ${ }^{14}$

O presente trabalho visou determinar os componentes voláteis de manga cv. Tommy Atkins, produzida no Vale do São Francisco, em três diferentes estádios de maturação (manga verde, semimadura e madura), utilizando-se microextração em fase sólida como técnica de extração.

\section{PARTE EXPERIMENTAL}

\section{Frutos e preparo das amostras}

Mangas verdes cv. "Tommy Atkins" (Mangifera indica L.), fisicamente uniformes e visualmente livres de doenças, foram adquiridas na fazenda Copa Fruit, localizada na cidade de Petrolina, no estado de Pernambuco (Brasil), em maio de 2008. Os frutos foram lavados com água corrente e mantidos a temperatura ambiente. As análises foram realizadas, em duplicata, com frutos verdes, semimaduros ("de vez") e maduros, os quais foram devidamente reconhecidos pelas mudanças na textura e na coloração da casca.

Nos períodos correspondentes a cada estádio de amadurecimento, os frutos foram cortados longitudinalmente e divididos em vários pedaços, utilizando-se faca de aço inoxidável. Alíquotas de $44 \mathrm{~g}$ foram homogeneizadas em solução saturada de cloreto de sódio $(100 \mathrm{~mL})$, utilizando-se microprocessador doméstico. Porções de $8 \mathrm{~mL}$ de cada suco produzido foram imediatamente transferidos para frascos de 40 $\mathrm{mL}$ e hermeticamente fechados com tampas rosqueáveis, contendo septo de silicone.

\section{Microextração em fase sólida (SPME)}

Os componentes voláteis foram extraídos por SPME através de amostrador manual, munido de fibra de sílica fundida Supelco (Bellefonte, EUA), $10 \mathrm{~mm}$ de comprimento, revestida com recobrimento polimérico 50/30 $\mu \mathrm{m}$ divinilbenzeno (DVB)/Carboxen/polidimetilsiloxano (PDMS). As extrações foram precedidas por pré-condicionamento das fibras a $270{ }^{\circ} \mathrm{C}$ durante $1 \mathrm{~h}$, no injetor do cromatógrafo, conforme instruções disponíveis no manual do fabricante.

\section{Cromatografia em fase gasosa acoplada à espectrometria de massas (CG-EM) e cromatografia em fase gasosa com detector de ionização por chama (CG-DIC)}

A análise por CG-EM foi realizada em um instrumento Shimadzu QP-2010 (Kioto, Japão), com impacto de elétrons a 70 eV, coluna DB5MS metilpolissiloxano (30 m x 0,25 mm x 1,0 $\mu \mathrm{m}$; J\&W Scientific Inc., Folsom, EUA), modo de injeção com divisão de fluxo de 1:50, durante toda a corrida, gás carreador hélio com fluxo de $1,05 \mathrm{~mL}$ $\min ^{-1}(53,5 \mathrm{Kpa})$ e velocidade linear constante de $37 \mathrm{~cm} \mathrm{~s}^{-1}$, temperatura do injetor $250{ }^{\circ} \mathrm{C}$, temperatura da linha de transferência 250 ${ }^{\circ} \mathrm{C}$. Programação do forno cromatográfico: temperatura inicial $40{ }^{\circ} \mathrm{C}$ por $10 \mathrm{~min}$, rampa de aquecimento de $10^{\circ} \mathrm{C} \mathrm{min}^{-1}$ até $130{ }^{\circ} \mathrm{C}$ e de 4 ${ }^{\circ} \mathrm{C} \min ^{-1}$ até $160^{\circ} \mathrm{C}$, isoterma de $10 \mathrm{~min}$, rampa de aquecimento de 4 ${ }^{\circ} \mathrm{C}$ min $^{-1}$ até $180^{\circ} \mathrm{C}$, temperatura mantida por $15 \mathrm{~min}$. A identificação dos compostos foi realizada pela análise dos padrões de fragmentação exibidos nos espectros de massas, tendo sido confirmada por comparação dos seus espectros de massas com aqueles presentes na base de dados fornecida pelo equipamento (NIST - 147.198 compostos), bem como através da comparação dos seus índices de retenção com os de compostos conhecidos, obtidos por injeção de uma mistura de padrões contendo uma série homóloga de alcanos $\mathrm{C}_{7}-\mathrm{C}_{22}$, e dados da literatura. ${ }^{15}$
A análise por CG-DIC foi realizada num instrumento Varian CP3800 (Palo Alto, EUA), com detector de ionização por chama (DIC), coluna CP-Sil 8 CB de fase estacionária metilpolissiloxano (30 m x 0,25 mm x 1,0 $\mu \mathrm{m}$; Varian Inc., Palo Alto, EUA), modo de injeção sem divisão de fluxo por $1 \mathrm{~min}$, gás carreador hidrogênio com fluxo constante de $1,5 \mathrm{~mL} \mathrm{~min}^{-1}$, temperatura do injetor $250{ }^{\circ} \mathrm{C}$, temperatura do detector $270{ }^{\circ} \mathrm{C}$. Programação do forno cromatográfico: temperatura inicial $40{ }^{\circ} \mathrm{C}$ por $10 \mathrm{~min}$, rampa de aquecimento de 10 ${ }^{\circ} \mathrm{C} \min ^{-1}$ até $130{ }^{\circ} \mathrm{C}$ e de $4{ }^{\circ} \mathrm{C} \min ^{-1}$ até $160{ }^{\circ} \mathrm{C}$, isoterma de $10 \mathrm{~min}$, rampa de aquecimento de $4{ }^{\circ} \mathrm{C} \mathrm{min}{ }^{-1}$ até $180{ }^{\circ} \mathrm{C}$, temperatura mantida por 15 min. A contribuição de cada composto volátil na mistura foi dada pela área relativa (\%) do seu respectivo pico no cromatograma registrado por DIC.

\section{Extração dos componentes voláteis}

O método de extração adotado foi desenvolvido por Cardeal e colaboradores, ${ }^{16}$ os quais otimizaram as condições de captação de voláteis para análises de frutas brasileiras e seus sucos, incluindo manga, utilizando-se fibras de SPME com recobrimento de polidimetissiloxano $(100 \mu \mathrm{m})$. As amostras foram aquecidas a $50{ }^{\circ} \mathrm{C} \mathrm{e}$ mantidas sob agitação durante 5 min (equilíbrio). Após este intervalo, a agitação foi interrompida, sendo introduzida a fibra, cujo tempo de exposição no headspace perdurou por $20 \mathrm{~min}$. Em seguida, a fibra foi injetada no cromatógrafo para dessorção térmica a $250{ }^{\circ} \mathrm{C}$ por 1 min e analisada por CG-EM e CG-DIC.

\section{Análise estatística}

Os resultados foram estatisticamente analisados pelo programa Microsoft Office ${ }^{\circledR}$ Excel 2003, através da análise de variância (ANOVA), pelo teste de comparação de médias, utilizando-se o teste de Tukey, com $\mathrm{P} \leq 0,05$.

\section{RESULTADOS E DISCUSSÃO}

Análises de CG-EM/DIC da composição volátil de mangas cv. Tommy Atkins, em três diferentes estádios de maturação, permitiram a identificação de 32 compostos, sendo identificados 20 componentes nos frutos verdes, 21 nos semimaduros e 22 nos maduros, correspondendo a aproximadamente $98 \%$ da constituição química, em termos de área relativa dos picos. A relação dos componentes identificados contendo seus respectivos índices de retenção e teores registrados, em cada estádio, encontra-se disposta na Tabela 1.

O baixo número de substâncias detectadas deve-se ao método de extração empregado, SPME. Em razão de ser uma técnica de captação de componentes presentes no headspace, SPME apresenta rendimento de extração limitado, apresentando geralmente um cromatograma simplificado, contendo menos de duas dezenas de compostos. ${ }^{4,8,17,19}$ Por outro lado, é possível identificar mais de 100 substâncias como constituintes do aroma de polpa de manga cv. Tommy Atkins através do método Likens-Nickerson (destilação-extração com solvente), cujas altas temperaturas aplicadas favorecem a volatilização dos componentes menos voláteis. ${ }^{18}$

A constituição química do extrato volátil de Tommy Atkins, obtido por destilação, mostra-se também qualitativamente mais rica do que a composição detectada por SPME, pois através do primeiro método são detectados vários compostos alcoólicos (ex.: 2-metil-butanol), éteres (ex.: 2-metil-furano), aldeídos (ex.: 3-hexenal), cetonas (ex.: 2-hexanona), ésteres de alto peso molecular (ex.: dodecanoato de etila), derivados alquil-benzênicos (ex.: mesitileno), além de compostos pirrólicos (ex.: 1-pentil-pirrol) e pirazínicos (tetrametil-pirazina), ${ }^{13,18}$ cuja formação em alimentos é atribuída à decomposição térmica. ${ }^{3}$ 
Tabela 1. Composição química volátil de manga cv. Tommy Atkins, produzida no Vale do São Francisco, em três estádios de maturação

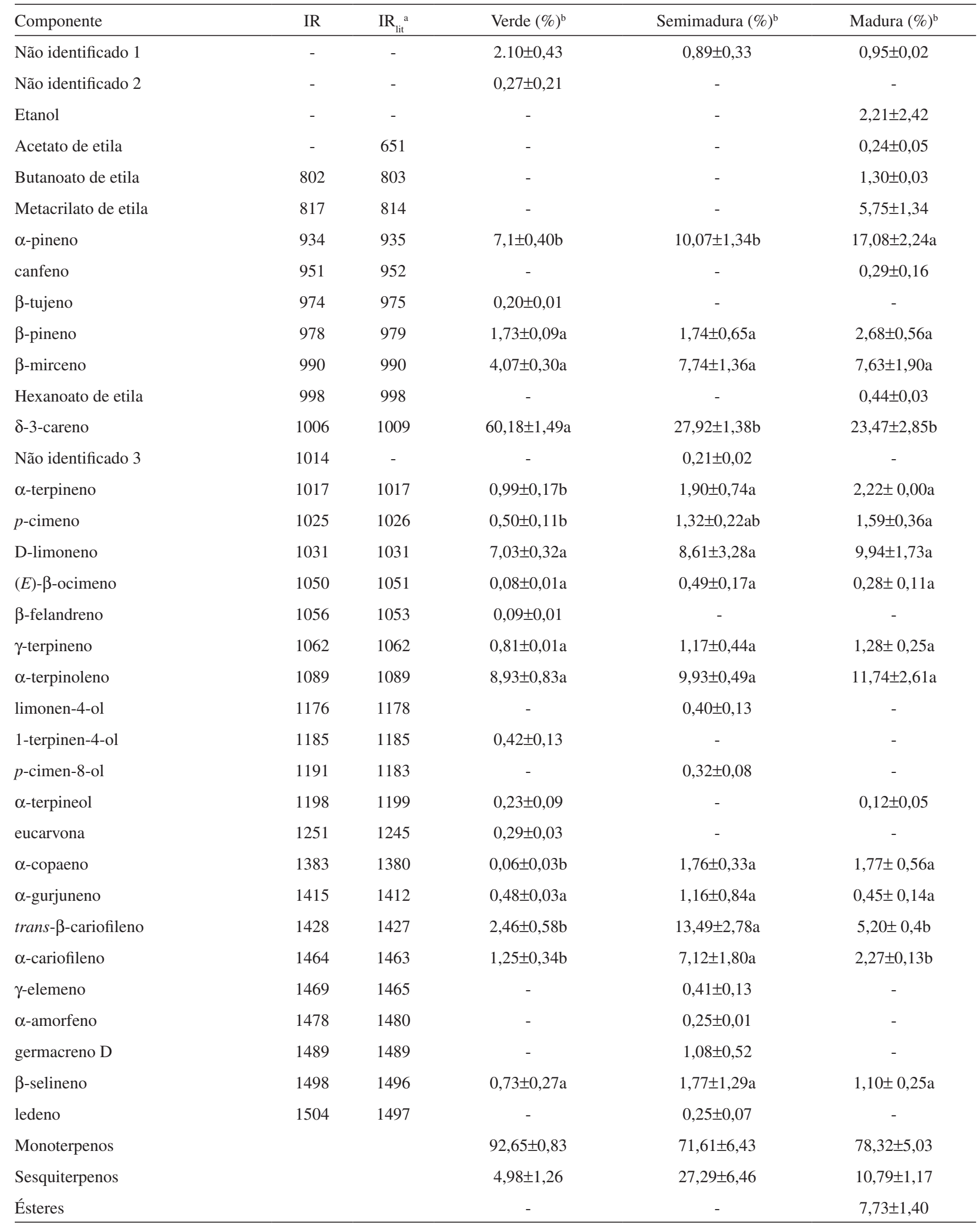

á́ndices de retenção exibidos pelos compostos em coluna DB-5MS ou similar, segundo dados disponíveis na base NIST. ${ }^{14}$ b Área relativa do pico no cromatograma obtido por CG-DIC. Médias seguidas de letra igual, na horizontal, não diferem significativamente no teste de Tukey a 5\% de probabilidade. 
Entretanto, os componentes voláteis extraídos por SPME representam com mais fidelidade o aroma autêntico da fruta percebido pelos receptores sensoriais humanos, porque não contêm contaminantes de solventes, artefatos ou substâncias de difícil volatilização (alto ponto de ebulição ou fortemente ligado à matriz). ${ }^{4}$

$\mathrm{O}$ aroma de manga cv Tommy Atkins foi significativamente influenciado pelo estádio de maturação, de tal forma que alguns compostos e até mesmo algumas classes químicas foram detectados exclusivamente em um destes estádios, comportando-se como marcadores químicos da maturação. Entretanto, independente da fase de amadurecimento, seu aroma foi constituído basicamente por mono (18) e sesquiterpenos (9), sendo uma característica marcante das variedades de manga do continente americano. ${ }^{8}$ Entre os monoterpenos, cinco foram do tipo oxigenado, porém não representaram sequer $1 \%$ da massa relativa.

Durante o amadurecimento, a concentração de monoterpenos diminuiu de 92,65 para $78,32 \%$, entretanto a proporção de sesquiterpenos cresceu de 4,98 para $10,79 \%$, alcançando o maior nível na manga semimadura $(27,29 \%)$. As concentrações de quatro monoterpenos ( $\alpha$-pineno, $\delta$-3-careno, $\alpha$-terpineno e $p$-cimeno) e três sesquiterpenos ( $\alpha$-copaeno, trans- $\beta$-cariofileno e $\alpha$-cariofileno) variaram significativamente. Ésteres $(7,73 \%)$ e etanol $(2,21 \%)$ foram detectados somente em frutos maduros, como produtos resultantes do metabolismo de ácidos graxos ou de aminoácidos ramificados. ${ }^{3,12}$ Estas mesmas variações já haviam sido observadas nas cultivares Kensington Pride e Keitt, exceto que a produção de monoterpenos permaneceu estável nesta última. ${ }^{12,13}$ Keitt pode ser considerada um bom referencial para Tommy Atkins, pois ambos possuem perfil aromático muito semelhante. ${ }^{13}$

$\delta$-3-careno foi o constituinte majoritário da manga cv. Tommy Atkins, contudo seu teor caiu significativamente com o avanço da maturação $(23,47 \%)$, reduzindo-se à mais metade da proporção inicial $(60,18 \%)$, tal como foi observado no amadurecimento das mangas Kensington Pride e Keitt, ${ }^{12,13}$ possivelmente devido à sua conversão em outros compostos. ${ }^{12}$

$\mathrm{O}$ segundo componente mais abundante variou conforme o estádio de maturação. Desse modo, $\alpha$-terpinoleno, trans- $\beta$-cariofileno e $\alpha$-pineno revezaram-se sucessivamente nesta posição, ao longo da maturação. Embora $\alpha$-terpinoleno $(10,25 \%)$ tenha sido proporcionalmente superado pelo $\alpha$-pineno $(15,50 \%)$, houve também incremento em seu teor na manga madura, exibindo o mesmo comportamento registrado em Kensington Pride e Keitt. ${ }^{12,13} \alpha$-Terpinoleno é o mais importante constituinte do aroma de Kensington Pride e de outras três cultivares cubanas. ${ }^{7,12}$

O nível máximo de trans- $\beta$-cariofileno $(17,86 \%)$ foi detectado na manga semimadura, coincidindo com o ápice da produção de sesquiterpenos, em relação aos quais trans- $\beta$-cariofileno representou cerca de metade da fração desta classe, em qualquer estádio de amadurecimento. Diferentemente da manga Kensignton Pride, ${ }^{12}$ a maturação favoreceu a produção de trans- $\beta$-cariofileno e de outros três sesquiterpenos, em comum: $\alpha$-copaeno, $\alpha$-gurjuneno e ledeno.

A manga verde foi caracterizada pela presença dos monoterpenos $\beta$-tujeno, $\beta$-felandreno e eucarvona, todavia os monoterpenos oxigenados limonen-4-ol e $p$-cimen-8-ol bem como os sesquiterpenos $\gamma$-elemeno, $\alpha$-amorfeno, germacreno $D$ e ledeno foram encontrados exclusivamente na manga semimadura. $\delta$-3-careno, pineno, $\beta$-mirceno são os principais responsáveis pela notas verdes no aroma de Tommy Atkins. ${ }^{11}$ Igualmente, $\beta$-ocimeno é considerado um dos componentes característicos de manga verde. ${ }^{3}$

A principal característica química adquirida pela manga madura foi o surgimento de ésteres alifáticos de cadeia curta (até 6 carbonos), os quais são considerados compostos de alto potencial odorífero e típicos do aroma frutal. ${ }^{11}$ Foram identificados quatro ésteres etílicos (acetato, butanoato, metacrilato e hexanoato), sendo o metacrilato de etila o componente mais abundante $(5,75 \%)$ e o único supostamente gerado a partir do metabolismo de aminoácidos. ${ }^{7}$
Análise olfatométrica de seis variedades de manga, entre elas Tommy Atkins, revelou que o butanoato de etila é o constituinte de maior impacto no aroma, mesmo quando presente em teores ínfimos. ${ }^{11}$ Acetato de etila $(71,32 \%)$ foi o principal composto liberado por frutos frescos e intactos de Tommy Atkins, mantidos em recinto fechado. ${ }^{20} \mathrm{O}$ amadurecimento provocou um incremento expressivo na produção de ésteres nas cultivares Keitt e Kensigton, atingindo um conteúdo total de ésteres de quase $40 \%$ nos frutos sobremaduros desta última. ${ }^{12,13}$

O monoterpeno canfeno $(0,29 \%)$ e etanol $(2,21 \%)$ foram detectados apenas na manga madura. A presença de etanol costuma ser atribuída à ocorrência de fermentação, comum em frutos em processo de deterioração, entretanto esta substância já foi detectada em frutos frescos de outras variedades de manga. ${ }^{21}$

Comparando-se a composição química do aroma de frutos maduros de Tommy Atkins determinada por outras técnicas de extração (métodos Likens-Nickerson, headspace dinâmico e estático), observou-se concordância apenas quanto à predominância de compostos monoterpênicos, cujos principais componentes foram em todos os casos o $\delta$-3-careno, seguido pelo $\alpha$-pineno. Entretanto, estes resultados demonstraram clara divergência em relação aos nossos resultados e também entre si, no tocante à presença de ésteres $(0,0$ $8,4 \%)$, à proporção de monoterpenos (70,0-96,9\%) e sesquiterpenos $(0,6-6,7 \%)$ e aos teores dos constituintes majoritários. Os teores de $\delta$-3-careno $(50,3-65,0 \%)$ foram equivalentes somente aos encontrados para frutos verdes, enquanto que $\beta$-mirceno $(0,1-2,1 \%)$, D-limoneno $(1,7-5,8 \%), \alpha$-terpinoleno $(1,5-4,8 \%)$ foram detectados em concentrações bem abaixo das determinadas em nosso estudo. Por outro lado, os valores de $\alpha$-pineno (6,0-25,0\%) e trans- $\beta$-cariofileno (0,3-6,0\%) foram similares aos nossos, em certas análises. ${ }^{11,13,18,19}$ Além do tipo de técnica empregada, outros fatores podem justificar as diferenças observadas, tais como procedência geográfica dos frutos e parte do fruto analisada (polpa com ou sem casca). É fato também que a subjetividade da avaliação do estádio de maturação torna esta classificação difícil e imprecisa, particularmente na fase final de amadurecimento, quando ocorrem transformações químicas rápidas e profundas. ${ }^{22}$

Apesar das mudanças verificadas no aroma de Tommy Atkins, provocadas pela maturação, dezesseis componentes estiveram presentes em todos os estádios de maturação, representando a constituição volátil básica desta variedade: $\alpha$ e $\beta$-pineno, $\beta$-mirceno, $\delta$-3-careno, $\alpha$-terpineno, $p$-cimeno, D-limoneno, $\beta$-ocimeno, $\gamma$-terpineno, $\alpha$-terpinoleno, $\alpha$-copaeno, $\alpha$-gurjuneno, trans- $\beta$-cariofileno, $\alpha$-cariofileno, $\beta$-selineno, além de um composto não identificado. Não por acaso, estes compostos são detectados no aroma de Tommy Atkins, independentemente do método de análise e condição ou origem dos frutos. ${ }^{8,10,11,13,18-20}$

\section{CONCLUSÃO}

A análise da composição volátil da manga Tommy Atkins permitiu caracterizar quimicamente o aroma desenvolvido pelos frutos ao longo do amadurecimento, o qual revelou ser constituído basicamente por monoterpenos. A presença de ésteres etílicos e etanol foi associada à maturação. Além disso, observou-se que alguns terpenos parecem ser biossintetizados preferencialmente em determinados estádios de maturação. Metacrilato de etila, limonen-4-ol, $p$-cimen8 -ol, eucarvona, $\gamma$-elemeno, $\alpha$-amorfeno estão sendo relatados pela primeira vez como componentes do aroma de manga Tommy Atkins.

\section{AGRADECIMENTOS}

À Embrapa/BID pelo suporte financeiro concedido (AGROFUTURO- 03.07.05.034.00.00), à empresa Copa Fruit pelos frutos fornecidos e ao Prof. A. M. E. Bezerra (UFC) pela orientação prestada na análise estatística. 


\section{REFERÊNCIAS}

1. Schieber, A.; Berardini, N.; Carle, R.; J. Agric. Food. Chem. 2003, 51 , 5006.

2. http://faostat.fao.org/site/567/DesktopDefault.aspx?PageID=567\#ancor, acessada em Outubro 2008; Pinto, A. C. Q. Em Agricultura Tropical: quatro décadas de inovações tecnológicas, institucionais e políticas; Albuquerque, A. C. S.; Silva, A. G., eds.; Embrapa Informação Tecnológica: Brasília, 2008, cap. 20.

3. Garruti, D. S. Em Perceptions on food and nutrition; Carioca, J. O. B.; Marx, F.; Jonas, R., eds.; Expressão Gráfica e Editora: Fortaleza:, 2006, cap. 25; Franco, M. R. B.; Aroma e sabor de alimentos: temas atuais, Livraria Varela: São Paulo, 2003; Plutowska, B.; Wardencky, W.; Food Chem. 2007, 101, 845.

4. Kataoka, H.; Lord, H. L.; Pawliszyn, J.; J. Chromatogr., A 2000, 880, 35; Valente, A. L. P.; Augusto, F.; Quim. Nova 2000, 23, 523; Ibáñez, E.; López-Sebastián, S.; Ramos, E.; Tabera, J.; Reglero, G.; Food Chem. 1998, 63, 281.

5. Singh, Z.; Lalel, H. J. D.; Nair, N.; Acta Hort. 2004, 645, 519.

6. Lalel, H. J. D.; Singh, Z.; Tan, S. C.; J. Hort. Sci. Biotechnol. 2003, 78, 131.

7. Pino, J. A.; Mesa, J.; Muñoz, Y.; Martí, M. P.; Marbot, R.; J. Agric. Food. Chem. 2005, 53, 2213

8. Malundo, T. M. M.; Baldwin, E. A.; Moshonas, M. G.; Baker, R. A.; Shewfelt, R. L.; J. Agric. Food. Chem. 1997, 45, 2187.
9. Adedeji, J.; Hartman, T. G.; Lech, J.; Ho, C. T.; J. Agric. Food. Chem. 1992, 40, 659 .

10. Andrade, E. H. A.; Maia, J. G. S.; Zoghbi, M. G. B.; J. Food Comp. Anal. 2000, 13, 27.

11. Lopes, D. C.; Fraga, S. R.; Rezende, C. M.; Quim. Nova 1999, 22, 31.

12. Lalel, H. J. D.; Singh, Z.; Tan, S. C.; Postharvest Biol. Technol. 2003, 27, 323.

13. MacLeod, A. J.; Snyder, C. H.; J. Agric. Food. Chem. 1985, 33, 380

14. Lebrun, M.; Plotto, A.; Goodner, K.; Ducamp, M. N.; Baldwin, E.; Postharvest Biol. Technol. 2008, 48, 122.

15. http://webbook.nist.gov/chemistry/, acessada em Agosto 2008.

16. Cardeal, Z. L.; Guimarães, E. M.; Parreira, F. V.; Food Addit. Contam. 2005, 22, 508 .

17. Silva, R. C.; Aguiar, P. M. S., Augusto, F.; Chromatographia 2004, 60 , 687.

18. Narain, N.; Galvão, M. S.; Acta Hort. 2004, 645, 671.

19. Franco, M. R. B.; Rodriguez-Amaya, D.; Lanças, F. M.; Ciênc. Tecnol. Aliment. 2004, 24, 165.

20. Hernández-Sánchez, G.; Sanz-Berzosa, I.; Casaña-Giner, V.; PrimoYúfera, E.; J. Appl. Ent. 2001, 125, 189.

21. Zhu, J.; Park, K-C.; Baker, T. C.; J. Chem. Ecol. 2003, 29, 899.

22. Taiz, L.; Zeiger, E.; Fisiologia vegetal, $3^{\text {a }}$ ed., Artmed: Porto Alegre, 2004. 